Reinzi Luz S. Bautista, MD

Ramon Antonio B. Lopa, MD

Arsenio Claro A. Cabungcal, MD

Anna Pamela C. Dela Cruz, MD

Tom Edward N. Lo, M.D.

Department of Otorhinolaryngology

Philippine General Hospital

University of the Philippines Manila

Correspondence: Dr. Arsenio Claro A. Cabungcal

Department of Otorhinolaryngology

Philippine General Hospital Ward 10

University of the Philippines Manila

Taft Avenue, Ermita, Manila 1000

Philippines

Phone: (632) 5548400 local 2152

Email: acabungca@@upm.edu.ph

The authors declare that this represents original material that is not being considered for publication elsewhere in full or in part, in print or electronic media; that the manuscript has been read and approved by all the authors, that the requirements for authorship have been met by each authors, and that each author believes that the manuscript represents honest work.

Disclosures: The authors signed disclosures that there are no financial or other (including personal) relationships, intellectual passion, political or religious beliefs, and institutional affiliations that might lead to a conflict of interest

Presented at the Philippine Society of Otolaryngology-Head and Neck Surgery Clinical Case Report Contest (2nd Place), Menarini Office, 4/F W Bldg. 11th Ave. cor. 28th St. Bonifacio High St. BGC Taguig, June 2, 2015.

\section{(c) (1) $(9$}

\title{
Tumoral Calcinosis in Secondary Hyperparathyroidism
}

\author{
ABSTRACT \\ describe its surgical management.

\section{Methods:}

$\begin{array}{ll}\text { Design: } & \text { Case Report } \\ \text { Setting: } & \text { Tertiary Public University Hospital } \\ \text { Patient: } & \text { One }\end{array}$

Objective: To report a case of tumoral calcinosis from secondary hyperparathyroidism and to

Results: A 34-year-old woman presented with progressively-enlarging bilateral upper extremity masses. Diagnostic tests revealed hyperfunctioning parathyroid glands. The patient underwent subtotal parathyroidectomy, right thyroid lobectomy with isthmusectomy, and transcervical thymectomy. Follow-up revealed marked decrease in parathyroid hormone, and progressive resolution of the tumoral calcinosis.

Conclusion: Subtotal parathyroidectomy and transcervical thymectomy have a role in the management of tumoral calcinosis, and in this case led to excellent post-operative results. The rare presentation of secondary hyperparathyroidism and intervention in this patient may have potential lessons for future management of similar cases.

Keywords: tumoral calcinosis, parathyroid, parathyroidectomy, thymectomy

Tumoral calcinosis is a rare condition involving periarticular soft tissue calcium deposition that may arise secondary to chronic renal insufficiency. ${ }^{1}$ We describe a case of tumoral calcinosis involving both shoulders and the right elbow of a woman who was being treated for chronic kidney disease due to chronic glomerulonephritis.

\section{CASE REPORT}

A 34-year-old woman with a seven-year history of weakness, occasional nausea and decreasing urine output was eventually diagnosed with chronic kidney disease Stage $\mathrm{V}^{2}$ due to chronic glomerulonephritis. She had twice-weekly hemodialysis and was maintained on carvedilol, amlodipine, iron and calcium supplementation, and erythropoietin.

During the course of treatment she developed firm nontender masses on both shoulders and her right elbow. (Figure 1, 2) Initial intact parathyroid hormone (PTH) was elevated at 1791pg/ $\mathrm{mL}$, and both calcium and phosphorus levels were elevated at $2.68 \mathrm{mmol} / \mathrm{L}$ and $2.94 \mathrm{mmol} / \mathrm{L}$, respectively. Calcium supplementation was discontinued and Sevelamer was started. A neck ultrasonogram revealed bilateral solid hyperechoic foci posterior to the thyroid gland, suggestive of parathyroid pathology. A Tc- $99 \mathrm{~m}$ sestamibi scan showed evidence of hyperfunctioning 
CASE REPORTS

Philippine Journal Of Otolaryngology-Head And Neck Surgery

Vol. 31 No. 1 JanuARY - June 2016

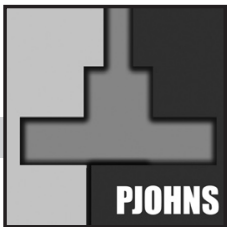

parathyroid tissue in the superior left thyroid bed. She was diagnosed with tumoral calcinosis secondary to chronic kidney disease. The masses progressed in size despite medical management, and she was referred to the Otorhinolaryngology - Head and Neck Surgery service for surgical treatment. Physical examination findings were confirmed radiographically. (Figure 3, 4, 5)

Bilateral parathyroid exploration, subtotal parathyroidectomy, right thyroid lobectomy with isthmusectomy, transcervical thymectomy and incision biopsy of the elbow mass were done in June 2014. (Figure 6) Bilateral superior and inferior parathyroid glands were identified, the right superior measuring $2.8 \times 2 \times 2.1 \mathrm{~cm}$ (enlarged), left superior $2.6 \times 1.6 \times 0.7 \mathrm{~cm}$ (enlarged), right inferior $1 \times 1 \times 1 \mathrm{~cm}$, and left inferior $1.2 \times 1 \times 1 \mathrm{~cm}$. (Figure 7) The specimens were consistent with parathyroid tissue on frozen section. A subtotal or $3 \frac{1}{2}$ parathyroidectomy was then performed, preserving $1 / 2$ of the left inferior parathyroid gland. A right thyroid lobectomy with isthmusectomy was performed following

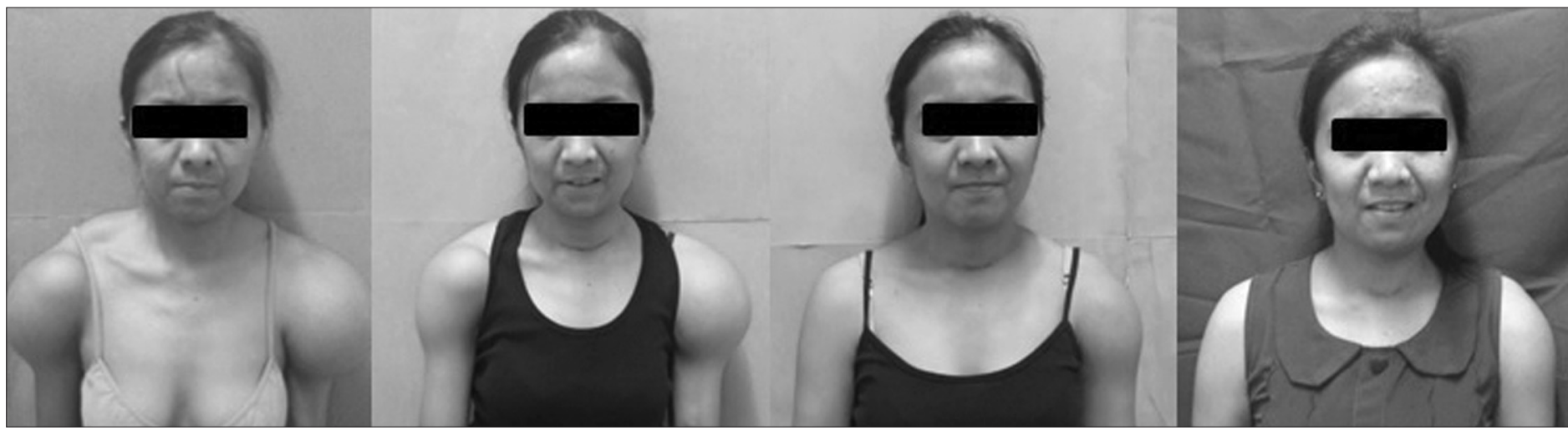

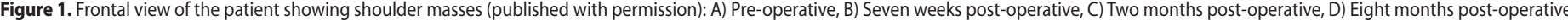

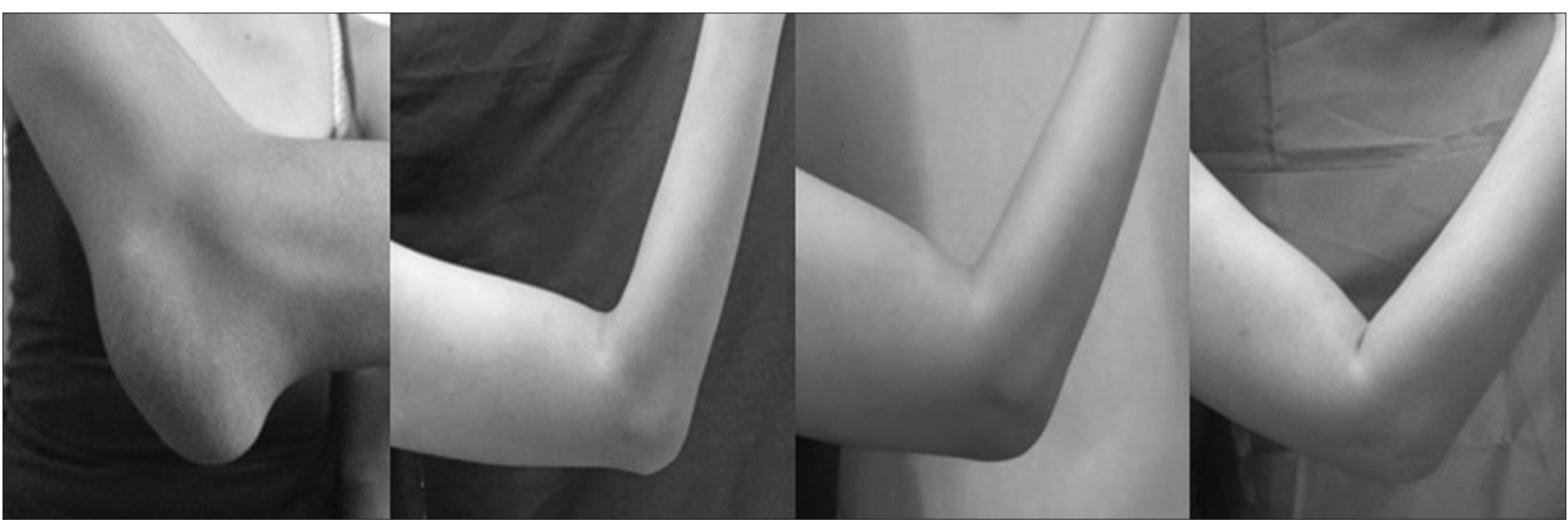

Figure 2. Right elbow mass: A) Pre-operative, B) Seven weeks post-operative, C) Two months post-operative, D) Eight months post-operative.

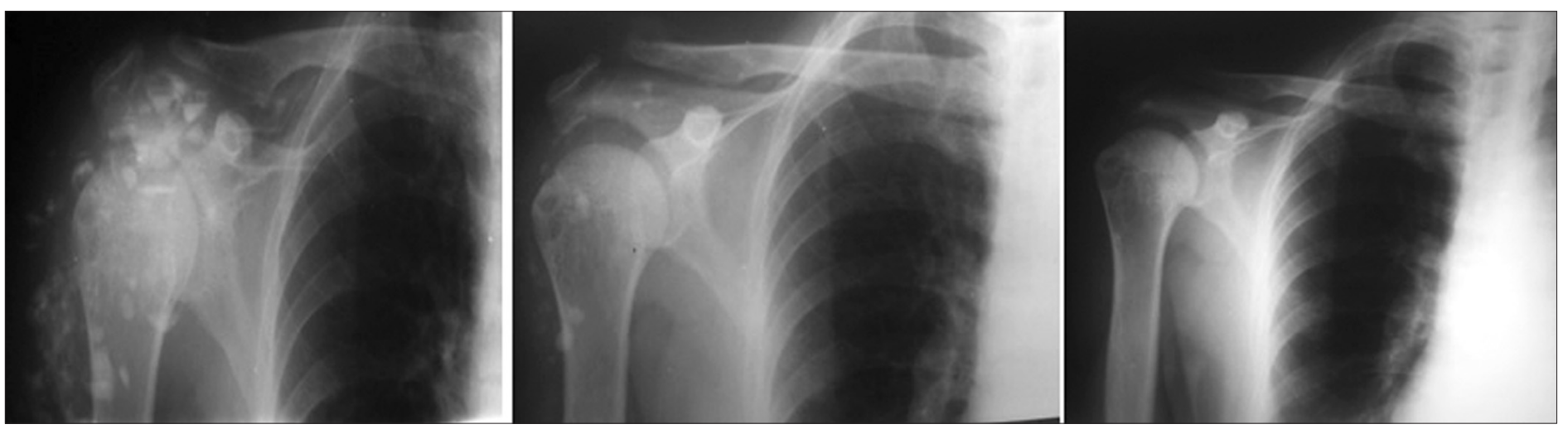

Figure 3. Radiograph (shoulder AP view) of right shoulder mass: A) Seven weeks post-operative, B) Two months post-operative, C) Eight months post-operative. 


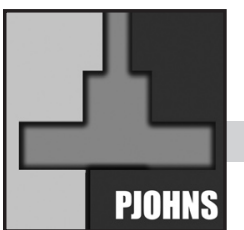

CASE REPORTS

Philippine Journal Of Otolaryngology-Head And Neck Surgery

Vol. 31 No. 1 JANUARY - JUnE 2016
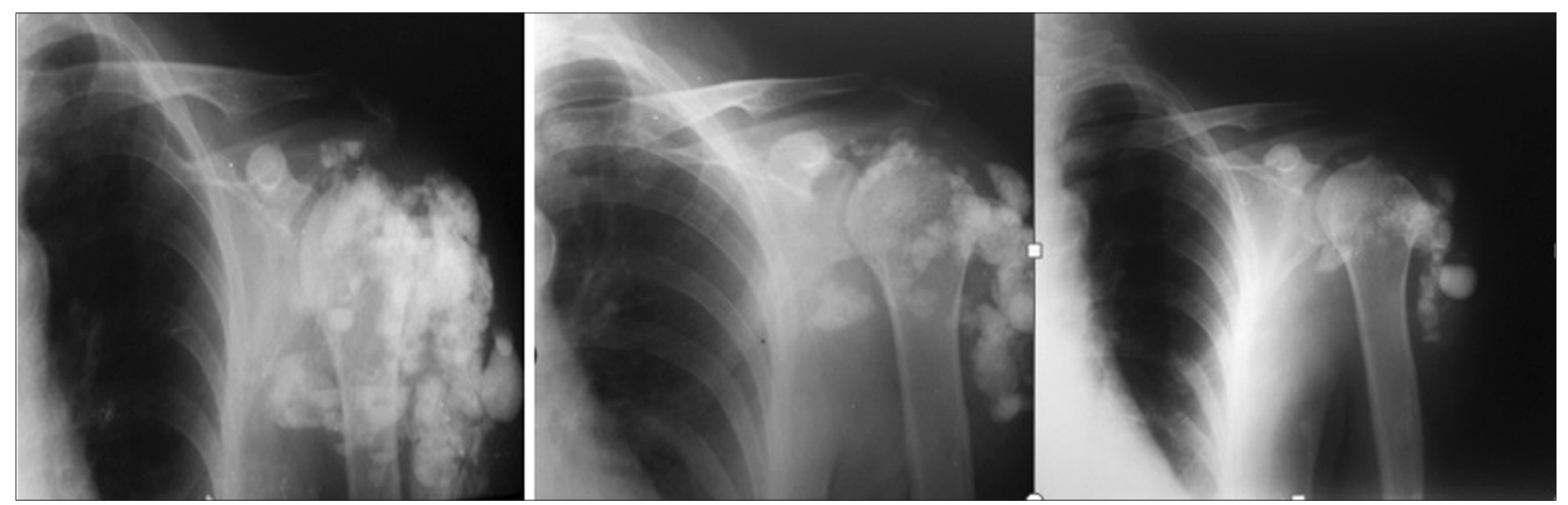

Figure 4. Radiograph (shoulder AP view) of left shoulder mass: A) Seven weeks post-operative, B) Two months post-operative, C) Eight months post-operative.
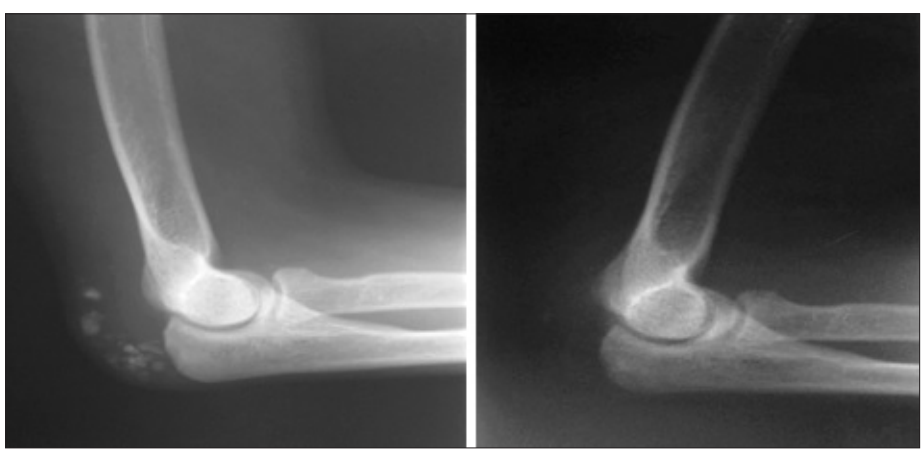

Figure 5. Radiograph (lateral view) of right elbow mass: A) Seven weeks post-operative, B) Two months post-operative.

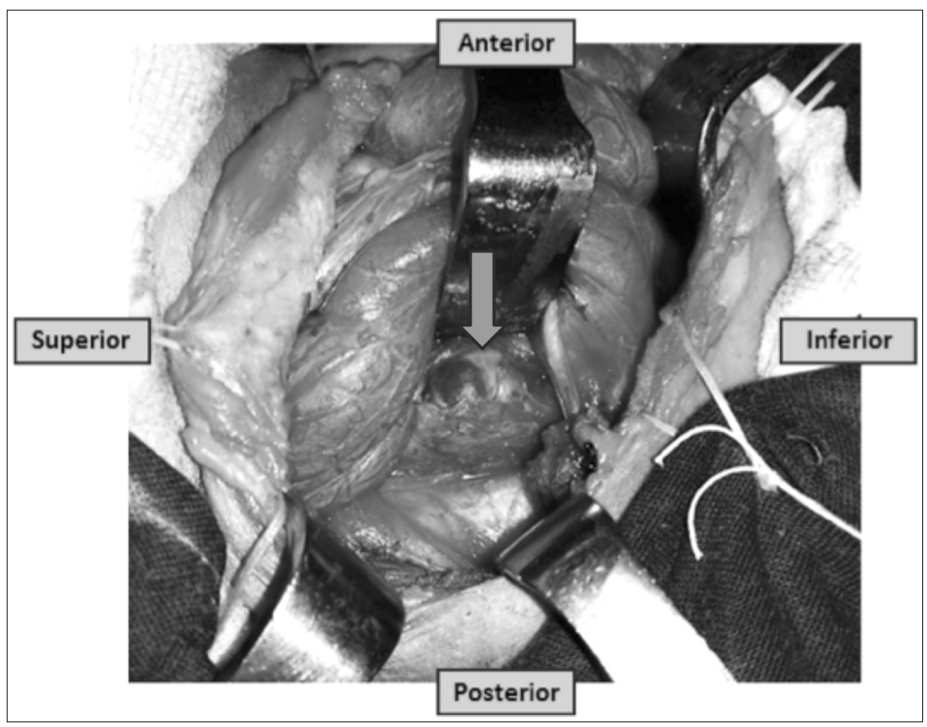

Figure 6. Parathyroid exploration, right superior gland (arrow pointing to gland).

the detection of a thyroid nodule measuring $0.6 \times 0.5 \times 0.5 \mathrm{~cm}$. Partial transcervical thymectomy by the Thoracocardiovascular Surgery service excised the left and right thymic horns with blunt dissection of intrathoracic thymic tissues beyond the innominate vein, obtaining a sample measuring $4.4 \times 2.5 \times 1.5 \mathrm{~cm}$. Incision biopsy of the right elbow mass, obtained $1 \times 1 \mathrm{~cm}$ of soft translucent whitish tissue.

Final histopathologic results showed parathyroid hyperplasia for the left superior and right superior parathyroid glands, and normal parathyroid tissue in the left inferior and right inferior tissue. (Figure 8) No diagnostic abnormality was noted in the dissected right thyroid lobe. Thymic remnants and four reactive lymph nodes were detected in the sample obtained from transcervical thymectomy, with no note of ectopic parathyroid tissue. The right elbow mass yielded fibrovascular connective tissue with calcifications, consistent with tumoral calcinosis. (Figure 9)

Post-operative calcium levels decreased to $1.7 \mathrm{mmol} / \mathrm{L}$ (from 2.69 $\mathrm{mmol} / \mathrm{L}$ ) and phosphorus levels to $2.03 \mathrm{mmol} / \mathrm{L}$ (from $2.94 \mathrm{mmol} / \mathrm{L}$ ). Rapid intact parathyroid hormone (PTH) was not available at our institution and thus an intraoperative PTH was not obtained. However, PTH levels dropped from a pre-operative $1791 \mathrm{pg} / \mathrm{mL}$ to $14.27 \mathrm{pg} / \mathrm{mL}$ post-operatively. The patient developed hypocalcemic symptoms and healthcare-associated pneumonia, both of which were managed and resolved during her hospital stay. She was discharged on the $19^{\text {th }}$ postoperative day with a serum calcium level of $2.04 \mathrm{mmol} / \mathrm{L}$.

The patient was maintained on oral calcium supplementation, and regular once to twice-weekly dialysis sessions. On follow-up, significant decrease in the size of her shoulder and elbow masses was noted, with her right shoulder mass being clinically undetectable four months post-operatively. (Figure 1, 2) At the eighth post-operative month, she reported near-total resolution of the masses. Post-operative radiography showed marked decrease in calcinosis for her elbows and shoulders. (Figure 3,4,5) Calcium levels have since normalized and she is currently awaiting a kidney transplant, which is the definitive management for her chronic kidney disease.

\section{DISCUSSION}

Tumoral calcinosis (TC) is a rare benign condition characterized by deposition of large hydroxyapatite or calcium phosphate crystals in periarticular soft tissue, usually around large joints. It usually manifests 
CASE REPORTS
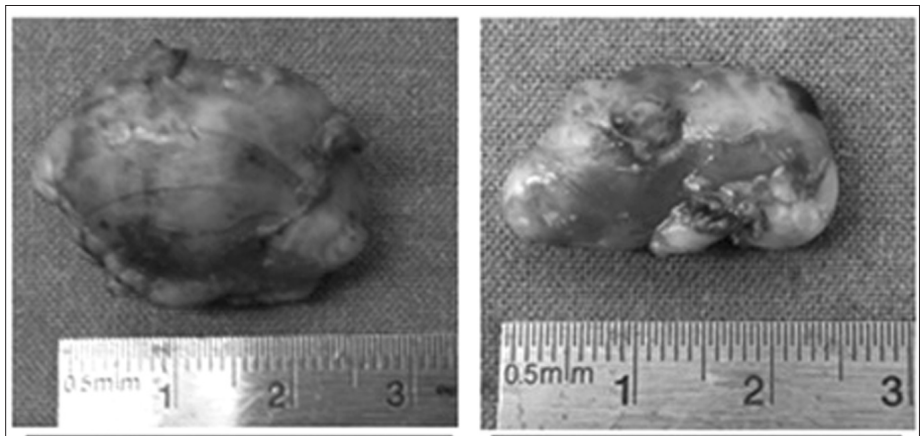

\section{Right superior parathyroid gland $2.8 \times 2 \times 2.1 \mathrm{~cm}$}

\section{Left superior parathyroid gland $2.6 \times 1.6 \times 0.7 \mathrm{~cm}$}

Figure 7. Intraoperative specimens, showing enlarged parathyroid glands.

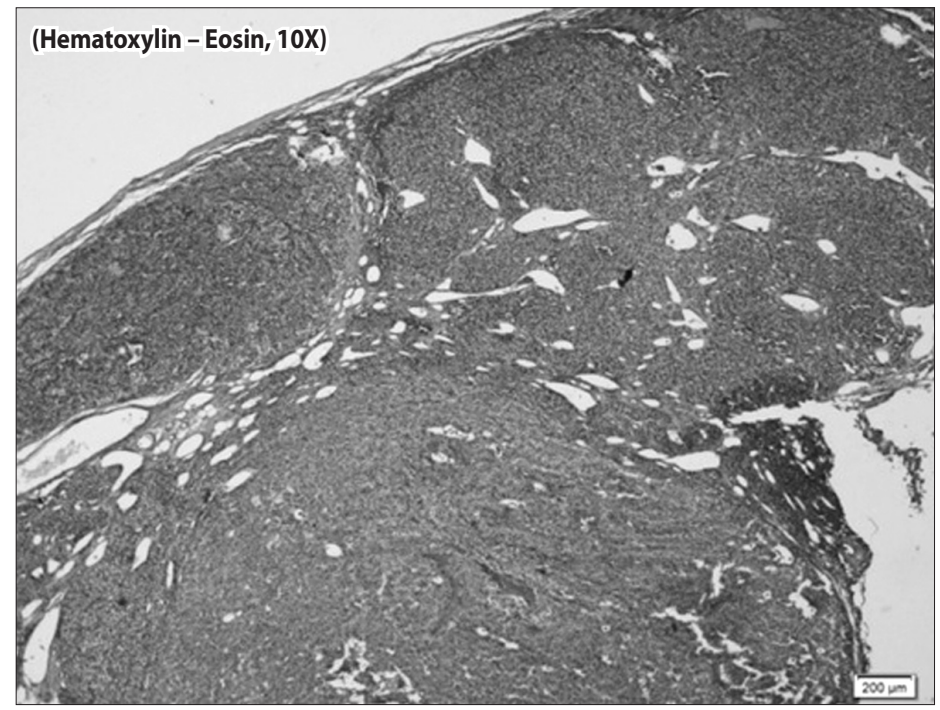

Figure 8. Parathyroid tissue, hematoxylin - eosin, low magnification (10X), showing hyperplasia. as a palpable asymptomatic tumor-like mass, with calcification limited to the soft tissues and not extending to erode underlying bony surfaces. The mechanism of calcinosis remains unknown; however, a pathogenesis-based classification of tumoral calcinosis describes three subtypes: 1) primary normophosphatemic, 2) primary hyperphosphatemic, and 3) secondary. ${ }^{3}$ Secondary tumoral calcinosis occurs in patients who have a concurrent disease capable of causing soft tissue calcification-- in this case, associated with the chronic kidney disease causing secondary hyperparathyroidism (SHPT). Renal insufficiency leads to reduced synthesis of 1,25- dihydroxy-Vitamin $D$ and decreased phosphate excretion resulting in hypocalcemia and hyperphospatemia. Consequently, parathyroid hormone (PTH) secretion increases resulting in parathyroid cell hyperplasia. ${ }^{4}$ The prevalence of periarticular calcinosis in chronic kidney disease patients is very small at $0.5-1.2 \% .^{5}$ The lesions have also mostly been described as varying in size from $2-10 \mathrm{~mm} .{ }^{6}$ This patient's tumoral calcinosis was much larger than commonly reported, with masses measuring $15 \times 12 \times 8 \mathrm{~cm}$ at the largest, which led to mass-effect limitation of extremity mobility and problems with cosmesis.

Primary conservative therapy for TC includes dialysis to address the underlying renal insufficiency, calcium supplementation, dietary phosphorus restriction and calcium-free phosphate binding agents, which possibly induce rapid mobilization of the bound calcium in the calcified mass. ${ }^{7}$ However, our patient did not respond to initial medical management, despite good compliance and regular follow-up. Uremic calcinosis has been noted to occur more commonly in patients on hemodialysis for more than three years. ${ }^{6}$ Our patient did present with the masses three years into dialysis, and thus failure of medical management was already a strong consideration.

Observational studies have estimated that up to $2.5 \%$ of patients on dialysis are eventually referred for parathyroidectomy each year. ${ }^{8}$

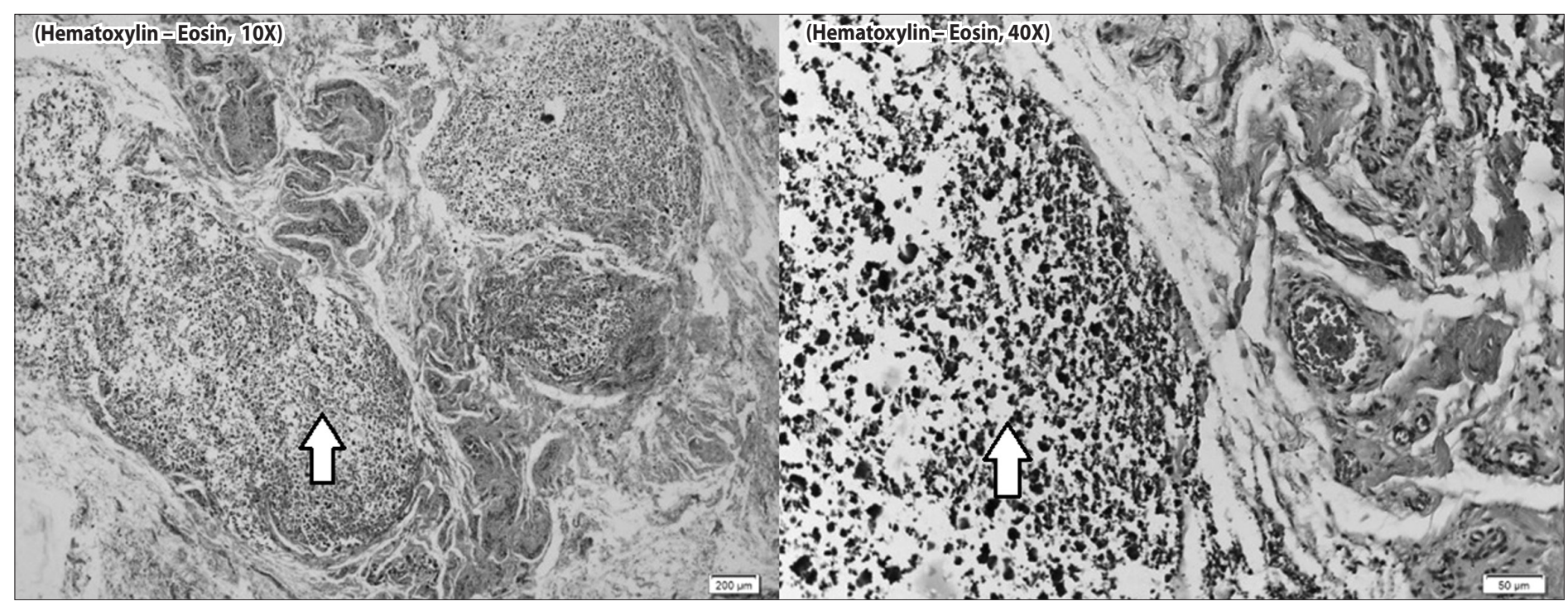

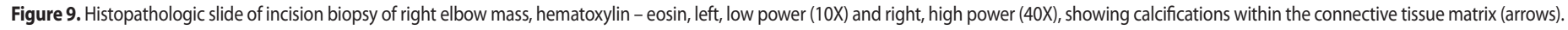




\section{CASE REPORTS}

The parathyroid glands help in maintaining calcium homeostasis by responding to changes in serum ionized calcium concentrations, and secrete PTH in response to a fall in serum calcium. ${ }^{9}$ Parathyroidectomy has been recommended in patients who have persistent hyperparathyroidism. Complete regression of TC, as well as correction of hypercalcemia, have been observed in patients who underwent subtotal parathyroidectomy. ${ }^{10-12}$

A major concern for the surgical management of the patient was achieving successful dissection of the parathyroid tissue involved. Secondary hyperparathyroidism has been known to persist or recur because of failure to locate supernumerary glands, which can be expected in $13 \%$ of patients with SHPT. ${ }^{13}$ Repeat parathyroid exploration is associated with more complications compared to initial explorations, ${ }^{14}$ and the most cost-effective and safest management of persistent or recurrent hyperparathyroidism is to avoid reoperation by performing a complete initial surgery. Localization studies such as ultrasound and sestamibi scanning are recommended, both of which the patient had pre-operatively. However, even sestamibi scanning may detect only between $35-65 \%$ of hyperplastic glands and identifies ectopic glands in around $5-10 \%$ of cases. ${ }^{15}$ Thus, a significant factor in successful surgery lies in the intraoperative localization of parathyroid glands, as well as dissecting the most common ectopic sites.

Ectopic parathyroid tissue has been noted most commonly within the thymus, as a consequence of the extensive embryologic migration of the inferior parathyroid glands. ${ }^{16}$ Routine thymectomy has not yet been established as a gold standard accompanying parathyroidectomy, but studies have shown promising results for the procedure. Intrathymic parathyroid tissue has been found in 33\% of patients with hyperparathyroidism who underwent transcervical thymectomy, including supernumerary glands in $11 \% .^{17}$ Intrathymic parathyroid tissue has also been found in $28.4 \%$ of patients who underwent re-operative parathyroidectomy due to persistent SHPT. ${ }^{18}$ Transcervical thymectomy involves removing one or both cervical tongues of the thymus, with an estimated $30-40 \%$ of thymic tissue removed. Post-operative hypocalcemia has been reported in $51 \%$ of patients compared to $25 \%$ in those undergoing parathyroidectomy alone. Other precautions for thymectomy include limiting bleeding and risk of injury to the recurrent laryngeal nerves. However, the transcervical approach still results in a high yield of parathyroid tissue in a relatively non-invasive way, compared to routine thymectomy that necessitates a sternotomy. This approach was deemed ideal for the patient, who preferred a minimally invasive surgery that would also lessen her chances of needing a subsequent operation to locate missed parathyroid tissue.

Intrathyroidal parathyroid tissue has also been found in up to $10 \%$ of patients with ectopic parathyroid glands ${ }^{18}$ and right thyroid lobectomy and isthmusectomy was performed after detection of a right thyroid nodule intraoperatively. The decision to perform a lobectomy at that point was also to lessen the need for re-operation, should the nodule have turned out to be pathologic.

Post-operative issues encountered included transient hypocalcemia, which was managed with intravenous calcium infusion, and development of healthcare-associated pneumonia which was attributed to the prolonged hospital stay. However, these issues were resolved and the patient is still on regular follow-up with Otorhinolaryngology - Head and Neck Surgery, Endocrinology, Orthopedic, and Neprhology services. Since the operation, eight months post-operatively, she has had remarkable progress to complete resolution of her tumoral calcinosis, with both clinical and radiographic evidence.

Tumoral calcinosis may present as a rare and devastating complication of renal insufficiency leading to secondary hyperparathyroidism. Despite good medical management, this disease can progress and necessitate surgical management. This case affirms that subtotal parathyroidectomy and transcervical thymectomy have a role in the management of tumoral calcinosis, and may lead to excellent post-operative results.

\section{REFERENCES}

1. Mohamed S, Jong-Hun J, Weon-Yoo K. Tumoral calcinosis of the foot with unusual presentation in an 11-year-old boy: a case report and review of literature. J Postgrad Med. 2007 Oct; 53(4): 247-9.

2. International Society of Nephrology. KDIGO 2012 Clinical Practice Guideline for the Evaluation and Management of Chronic Kidney Disease. Kidney Int Suppl. 2012; (3)1: 5-6.

3. Smack DP, Norton SA, Fitzpatrick JE. Proposal for a pathogenesis-based classification of tumoral calcinosis. Int J Dermatol. 1996 Apr; 35(4):265-71.

4. Goodman WG. Medical management of secondary hyperparathyroidism in chronic renal failure. Nephrol Dial Transplant. 2003 Jun; (18 Suppl 3): iii2-iii8.

5. Franco M, Van Elslande L, Passeron C, Verdier JF, Barrillon D, Cassuto-Viguier E, Pettelot $\mathrm{G}$, Bracco J. Tumoral calcinosis in hemodialysis patients: a review of three cases. Rev Rhum Engl Ed. 1997 Jan; 64(1):59 - 62.

6. Huang Y, Chen CY, Yang CM, Yao MS, Chan WP. Tumoral calcinosis-like metastatic calcifications in a patient on renal dialysis. Clin Imaging. 2006 Jan-Feb; 30(1):66-68.

7. Van Straten A, Hoogeveen E, Khan S, De Scheperr A. Unusual presentation of tumoral calcinosis in chronic renal failure: a case report. Eur J Radiol. 2005; 53: 81-85.

8. Decker PA, Cohen EP, Doffek KM, Ashley BA, Bienemann ME, Zhu YR, et al. Subtotal parathyroidectomy in renal failure: still needed after all these years. World J Surg. 2001 Jun; 25(6): 708-12.

9. Darr A, Sritharan N, Pellitteri P, Sofferman R, Randolph G. Management of Parathyroid Disorders. In: Flint PW, Haughey BH, Lund VJ, Niparko JK, Richardson MA, Robbins KT, Thomas JR. Cummings Otolaryngology Head and Neck Surgery. 6th Ed. Philadelphia: Mosby Elsevier; 2015. p. 1929-1955.

10.Mockel G, Buttgereit F, Labs K, Perka C. Tumoral calcinosis revisited: pathophysiology and treatment. Rheumatol Int. 2005 Jan; 25(1): 55-9.

11. Hiramatsu R, Ubara Y, Hayami N, Yamanouchi M, Hasegawa E, Sumida K, et al Occurrence of new bone-like tissue formation in uremic tumoral calcinosis. Bone. 2013 Feb; 52(2): 684-688.

12.Thakur A, Hines OJ, Thakur V, Gordon HE. Tumoral calcinosis regression after subtotal parathyroidectomy: A case presentation and review of the literature. Surgery. $1999 \mathrm{Jul}$; 126(1): 95-98.

13. Akerstrom G, Malmaeus J, Berstrom R. Surgical anatomy of human parathyroid glands. Surgery. 1984 Jan; 95(1):14-21.

14.Caron NR, Sturgeon $\mathrm{C}$, Clark OH. Persistent and recurrent hyperparathyroidism. Curr Treat Options Oncol. 2004 Aug; 5(4): 335-45

15. de la Rosa A, Jimeno J, Membrilla E, Sancho J, Pereira JA, Sitges-Serra A. Usefulness of preoperative Tc-mibi parathyroid scintigraphy in secondary hyperparathyroidism. Langenbecks Arch Surg. 2008 Jan; 393(1):21-24.

16. Ritter HE, Milas M. Bilateral parathyroid exploration for hyperparathyroidism. Op Tech Otolaryngol. 2009; 20: 44-53.

17. Welch K, McHenry CR. The role of transcervical thymectomy in patients with hyperparathyroidism. Am J Surg. 2012 Mar; 203(3):292-5.

18.Schneider R, Bartsch DK, Schlosser K. Relevance of bilateral cervical thymectomy in patients with renal hyperparathyroidism: analysis of 161 patients undergoing reoperative parathyroidectomy. World J Surg. 2013 Sep; 37(9):2155-61. 